\title{
GESTIONANDO EL PATRIMONIO EDIFICADO DE LOS VIÑEDOS DE ICA: TURISMO RURAL Y MUSEOS COMUNITARIOS ${ }^{[*]}$
}

\author{
MANAGING THE BUILT HERITAGE OF THE VINEYARDS OF ICA: \\ RURAL TOURISM AND COMMUNITY MUSEUMS
}

NATALIA IJU IREIJO $0^{(\star \star)}$ Y ANA ALEMÁN CARMONA ${ }^{(* \star *]}$

Fecha de recepción: 18 de agosto de 2015

Fecha de aprobación: 07 de octubre de 2015

\begin{abstract}
RESUMEN
La presente investigación ofrece una alternativa de desarrollo local mediante la fusión de dos planteamientos turísticos. El primero se centra en los museos de corte comunitario o participativo, por ejemplo el Museo Comunitario de Pisac en Cusco y el de Leymebamba en Amazonas, entre otros. Se debe destacar que no existen muchos aún, a pesar de que esta tendencia museológica viene trabajándose a nivel internacional desde los años 70 . El segundo tiene que ver con el turismo rural, que busca también la participación activa de los pobladores locales a través del desarrollo de actividades relacionadas a su entorno. En este contexto se plantea la posibilidad de crear museos comunitarios gestionando el patrimonio edificado de los viñedos de Ica y complementando esta propuesta con el turismo rural. Cabe resaltar que el enfoque de ambos planteamientos pretende contribuir de manera muy activa al desarrollo de la población del lugar y la sostenibilidad.
\end{abstract}

\section{PALABRAS CLAVE}

Museos comunitarios, turismo rural, viñedos

\begin{abstract}
Our research proposes a local development alternative that combines two touristic plans. The first one is focused on participative community museums, as the ones in Pisac, Cuzco and Leymebamba, Amazonas, among some others. There are not many yet, although this international museological trend has been present since the 70s. The second one focuses on rural tourism, looking for the active involvement of the local population through activities related to their daily environment. Within this context, we propose the creation of participative community museums that manage the built heritage of Ica's vineyards, along with the promotion of rural tourism. This approach intends to promote local development and sustainability.
\end{abstract}

\section{KEYWORDS}

Participative community museums, rural tourism, vineyards

$\left(^{*}\right)$ Este artículo forma parte de una investigación realizada por ambas autoras. Los datos han sido tomados de la tesis doctoral San Juan: Espacio Turístico Rural (2012), que tuvo una duración de aproximadamente un año y medio bajo la dirección del Dr. Henrique Urbano, de la Universidad de San Martín de Porres, y se complementó con bibliografía sobre museos y de la provincia de Ica.

$\left(^{* *}\right)$ Doctora en Turismo; magíster en Gestión Cultural, Patrimonio y Turismo; y licenciada en Turismo y Hotelería por la Universidad de San Martín de Porres. Investigadora, consultora, docente universitaria y especialista en turismo rural. Directora de Bunka Experiencias, empresa dedicada al desarrollo de capacidades educativas e investigación. Contacto: nataliaiju@gmail.com

$\left.{ }^{(* * *}\right)$ Magíster en Gestión Cultural, Patrimonio y Turismo por la Universidad de San Martín de Porres, doctoranda en Turismo por la misma casa de estudios. Docente en diversas universidades y especialista en Museología. Contacto: aaleman63@gmail.com 
devenir Vol. 2, N4, JULIO-DICIEMBRE 2015, Pp. 9-26 - Estudios I ISSN 2312-7570

UNIVERSIDAD NACIONAL DE INGENIERÍA, LIMA

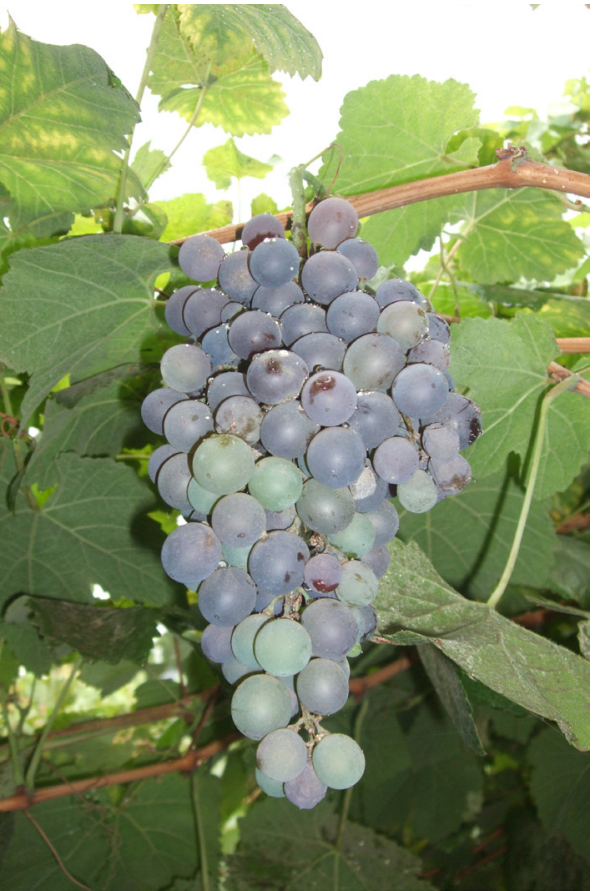

Figura 1. Uva quebranta, bodega Tres Generaciones.

Fuente. Fotografía tomada por Saida Crisóstomo, 2013

Figura 2. Botija en la bodega El Catador.

Fuente. Archivo personal, 2013
Esta investigación aborda dos conceptos que buscan la participación social activa en sus aplicaciones. Por un lado, está el concepto de 'ecomuseo' o 'museo participativo', que si bien no resulta novedoso en el quehacer museístico mundial, en el entorno peruano todavía no ha llegado a cimentarse o convertirse en un modelo recurrente. Por otro lado, está el turismo rural comunitario, una práctica que va más allá del disfrute de la naturaleza y de la hospitalidad de las comunidades receptoras. En ambos casos la comunidad es quien debe estar de acuerdo con lo que se propone, y ser la principal involucrada y beneficiaria.

En ese sentido, en este texto se elabora una propuesta de cómo un ecomuseo del vino puede ayudar a poner en valor el patrimonio edificado rural de Ica. Con ello también se conseguiría crear un atractivo para una oferta aparentemente limitada. Además de disfrutar del campo y de las actividades propias del medio rural, esta propuesta podría dar a conocer un aspecto cultural de los pobladores: la elaboración vitivinícola, los usos y costumbres asociados, las tradiciones orales y el uso de los espacios, entre otros aspectos que se pueden poner en valor.

Para ello, se empezó por entrevistar a algunos pobladores, especialmente a aquellos que ya están trabajando emprendimientos de turismo rural. De esta manera se pudo obtener información sobre el interés existente en hacer un museo de este corte en la zona, considerando que los ecomuseos pueden fácilmente formar parte de las actividades que se suelen proponer dentro de la práctica del turismo rural comunitario.

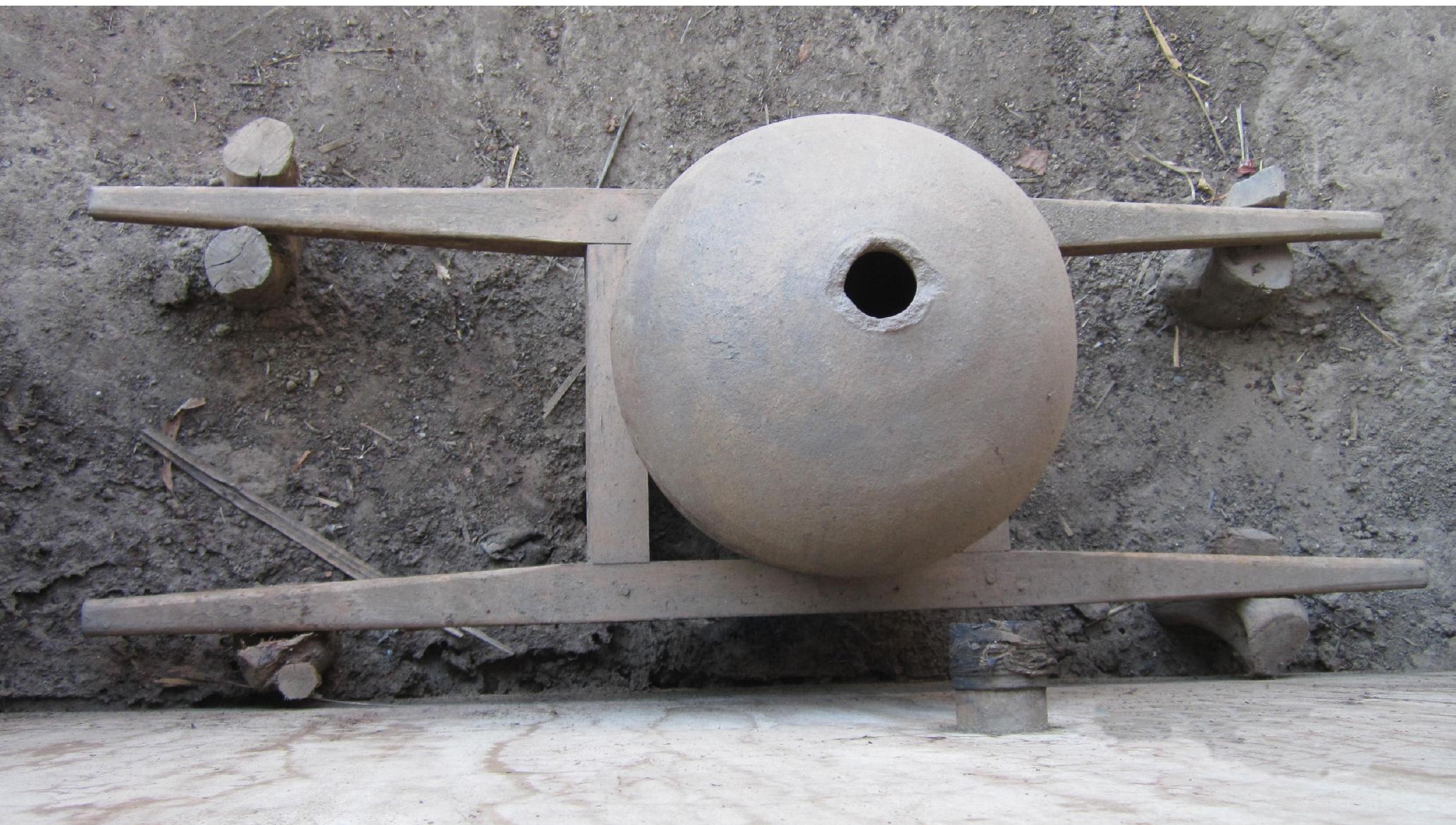




\section{Ica, sus Viñedos y la Nueva Museología}

El departamento de Ica tiene una superficie de $21^{\prime} 327,83 \mathrm{~km}^{2}$, área que representa el $1,7 \%$ del territorio peruano, donde habita el 2,57\% de la población del país. La provincia de lca se encuentra ubicada en la región costa del departamento; sin embargo, comprende también parte de la región andina en tres distritos (Yauca del Rosario, San José de los Molinos y Santiago). El departamento está compuesto por los siguientes distritos: Ica, La Tinguiña, Los Aquijes, Ocucaje, Pachacutec, Parcona, Pueblo Nuevo, Salas, San José de los Molinos, San Juan Bautista, Santiago, Subtanjalla, Tate, Yauca del Rosario (Municipalidad Provincial de Ica, 2008). La provincia de Ica limita por el Norte con la provincia de Pisco, por el Este con la provincia de Huaytará (Departamento de Huancavelica) y de Palpa, por el Sur con la provincia de Nasca, y por el Oeste con el océano Pacífico (Municipalidad Provincial de Ica, 2008). Su capital es la ciudad de Ica, cuya altitud fluctúa entre los 325 y los 3290 m.s.n.m. (Municipalidad Provincial de Ica, 2008).
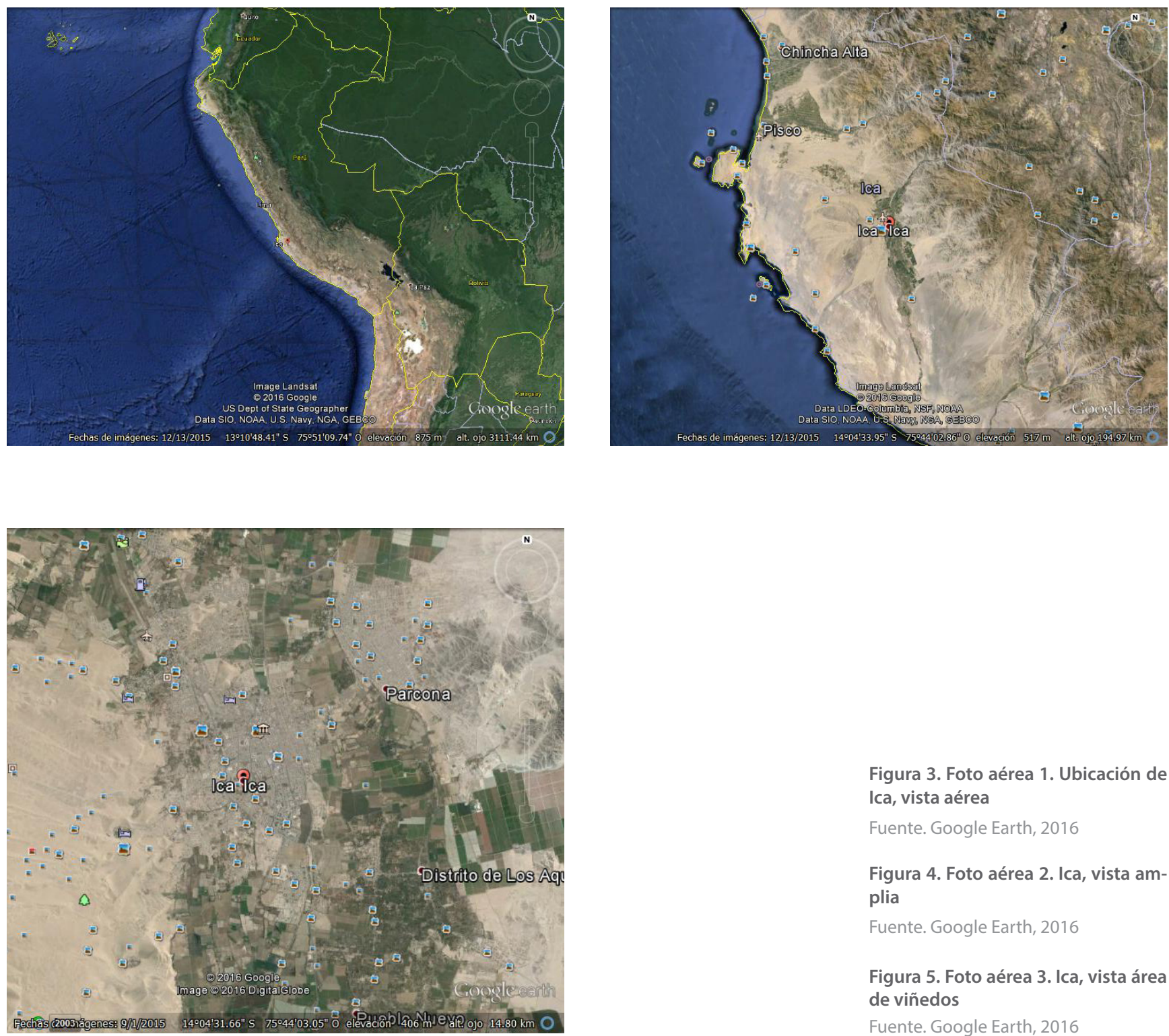

Figura 3. Foto aérea 1. Ubicación de Ica, vista aérea

Fuente. Google Earth, 2016

Figura 4. Foto aérea 2. Ica, vista amplia

Fuente. Google Earth, 2016

Figura 5. Foto aérea 3. Ica, vista área de viñedos

Fuente. Google Earth, 2016 
La configuración fisiográfica y geográfica es variada. Esta variabilidad condiciona la existencia de diversos pisos ecológicos: las zonas Chala, Yunga y Quechua, que, a su vez, permiten la existencia de varios microclimas que albergan variedad de flora y fauna silvestre, y de animales domésticos (Municipalidad Provincial de Ica, 2008). El $89 \%$ del área departamental corresponde a la costa y solo el $11 \%$ del área a la sierra (Sotil, 2005).

Para Sotil, el clima es benigno durante la mayor parte del año:

El clima es templado en los meses de otoño, invierno y primavera y cálido desértico en el verano. La humedad atmosférica es alta en el litoral y disminuye hacia el interior. Las precipitaciones son escasas. Solo excepcionalmente se producen lluvias de gran intensidad, pero son de corta duración. En la sierra las lluvias son estacionales y de mayor intensidad. Las temperaturas máximas absolutas alcanzan $32,3^{\circ} \mathrm{C}$ en Ica y $27,4^{\circ} \mathrm{C}$ en Pisco y las mínimas absolutas están entre los $9,8^{\circ} \mathrm{C}$ en Ica y $12,6^{\circ} \mathrm{C}$ en Pisco. $(2005$, p. 32)

El suelo agrícola, junto con el agua, clima y otros factores, es bastante importante porque permite el desarrollo de la agricultura. Los suelos son fértiles, por lo que el rendimiento agrícola resulta provechoso. Los productos obtenidos se comercializan en mercados nacionales e internacionales, y muchos de ellos son transformados en empresas de manufactura. Entre los principales problemas en este rubro están la insuficiencia de agua y el uso indiscriminado de químicos. Cabe resaltar que la carencia de agua también afecta a la ganadería (Municipalidad Provincial de Ica, 2008).

En Ica existen numerosas haciendas, entre ellas Huamaní, Trapiche, Hacienda Grande, Yancay, Tacama, San Martín, Chavalina, Galagarza, Belén, Santa Rosa, Esperanza, San Tadeo, San Miguel, La Unión, la Máquina, Cordero, San Jerónimo, Checa, Vista Alegre, Aña-

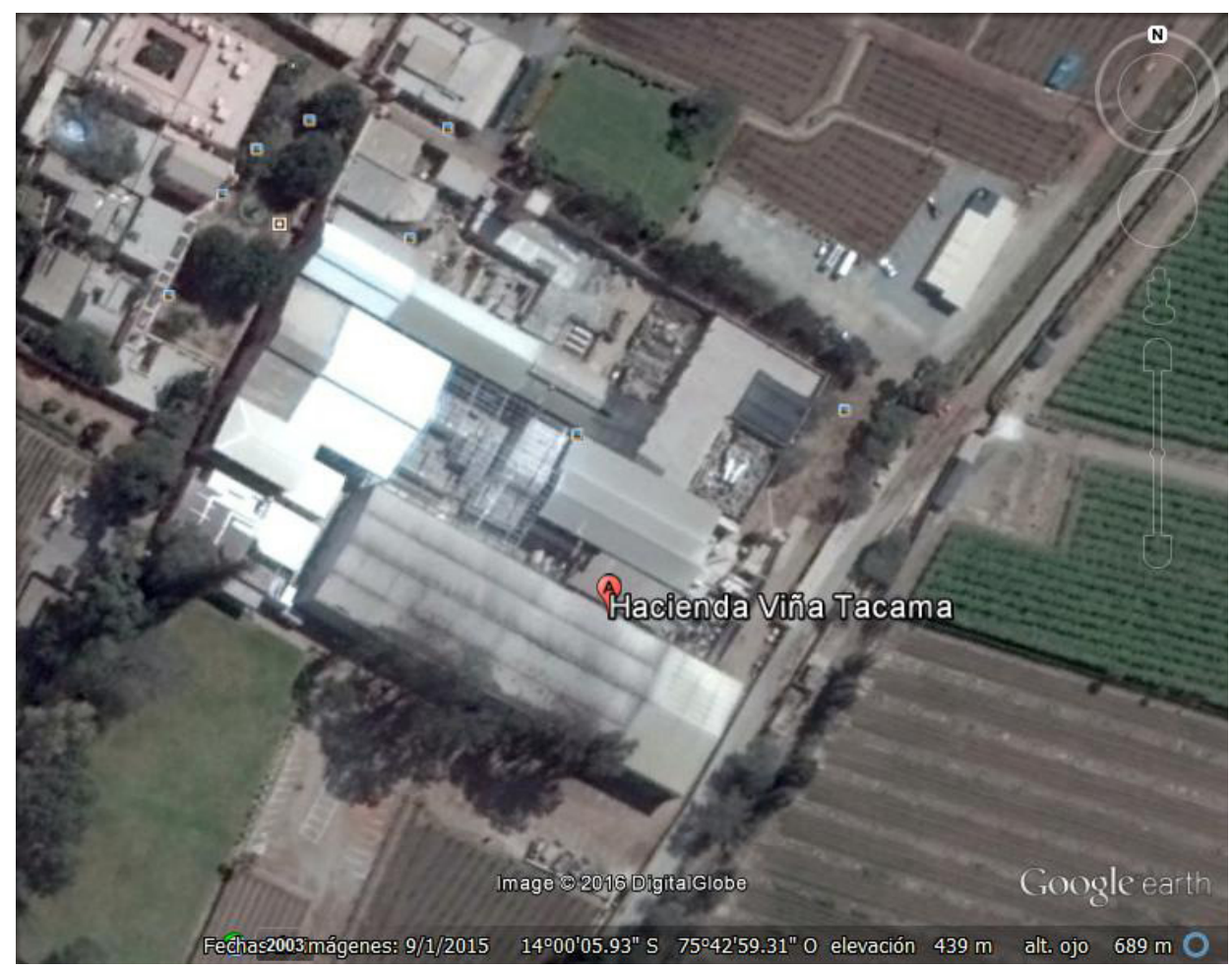

Figura 6. Foto aérea 4. Viñedo Tacama. Vista aérea Fuente. Google Earth, 2016 


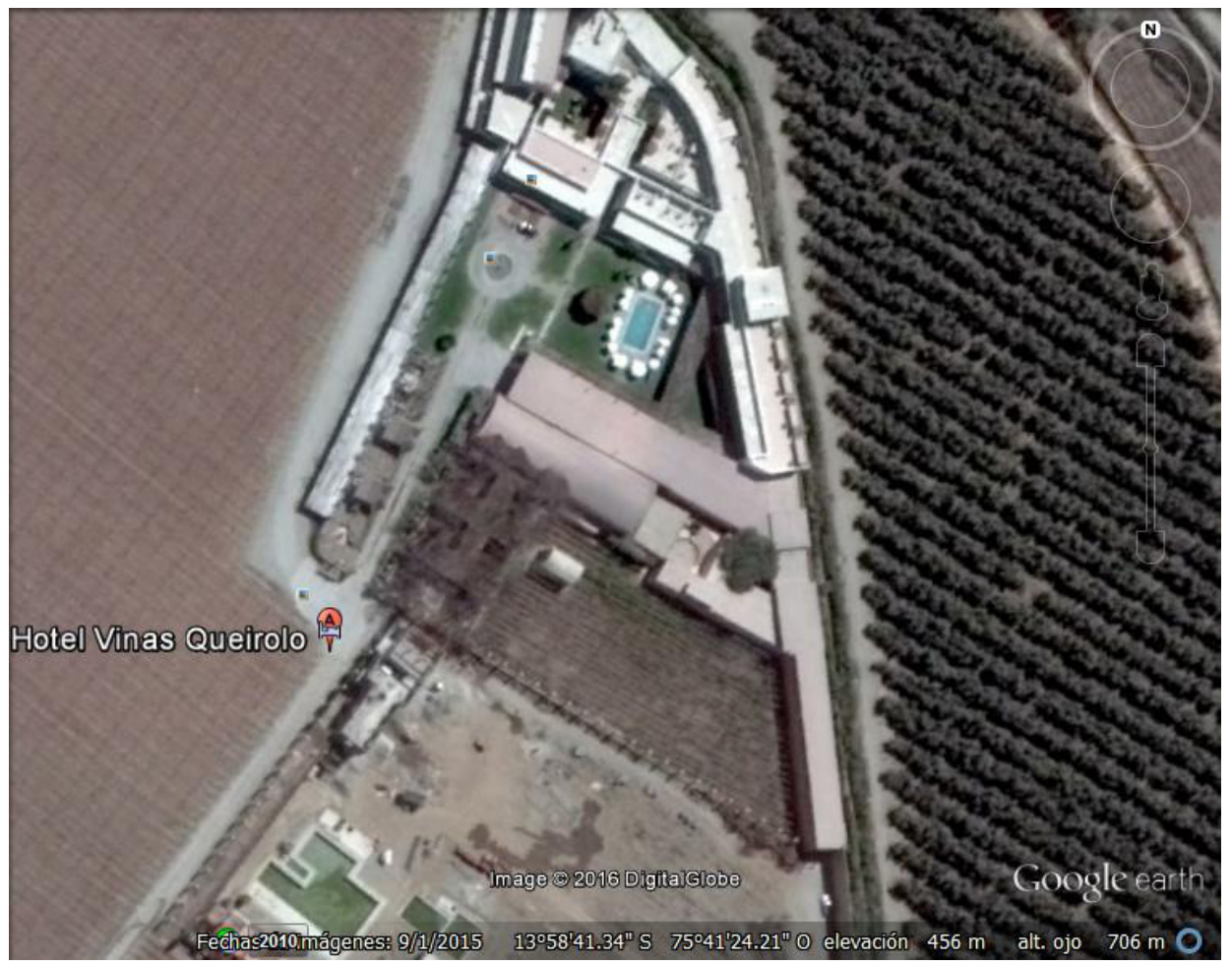

Figura 7. Foto aérea 5. Viñedo Queirolo. Vista aérea

Fuente. Google Earth, 2016

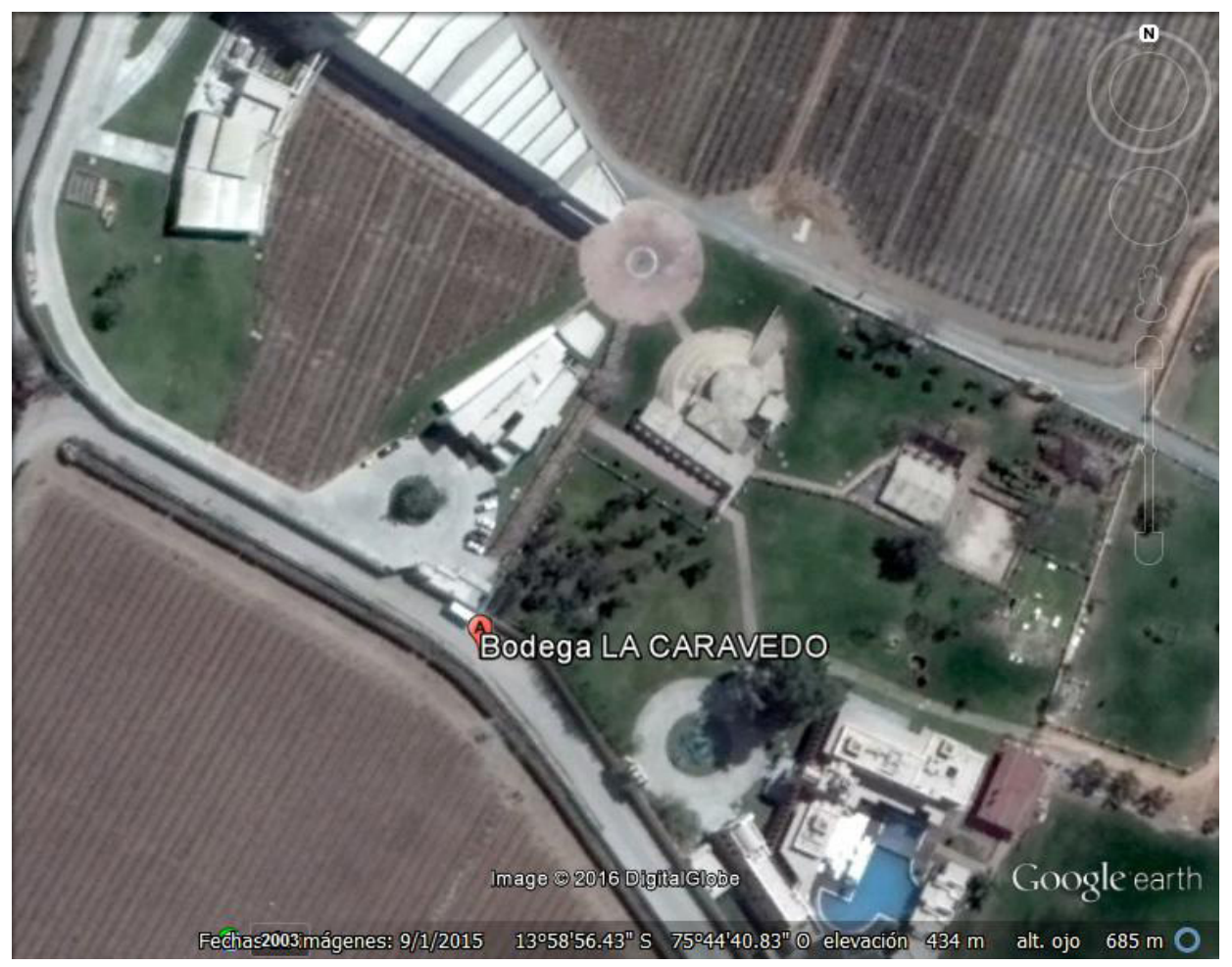

Figura 8. Foto aérea 6. Viñedo La Caravedo. Vista aérea

Fuente. Google Earth, 2016 
devenir Vol. 2, N4, JULIO-DICIEMBRE 2015, Pp. 9-26 - Estudios I ISSN 2312-7570

UNIVERSIDAD NACIONAL DE INGENIERÍA, LIMA

Figura 9. Botijas en la bodega El Catador

Fuente. Archivo personal, 2013 mía, San Idelfonso, Margas, La Vela, Parcona, Santa Apolina, Rivera, Carrizales, Santa Gertrudis, Guerrero, La Bolívar, Pampa Versalles, Orongo, Los Ángeles, Machacona, Los Pobres, La Caravedo, Saraja, Palazuelos, Rodamonte, La Palma, San José, Centeno, Chacarilla, Lovera, Poruma, Casablanca, La Primavera, Baldeón, Santa Bárbara, San Ramón, Tacaraca, Santa Rita, San Cayetano, Santiago, Tajahuana, Santiaguillo, Tronquitos, Ocucaje, La Venta, Comunidad Achirana, Quilloay. Además, están las comunidades que se dedican a la producción de piscos: Comatrana, Cachiche, Lujaraja, Santa Lucía, Sacta, Cantoral.

Entre sus atractivos turísticos se encuentran los siguientes (Sotil, 2005):

- Museo Regional de Ica. Exhibe una colección arqueológica que corresponde a las culturas que se desarrollaron en la región desde la época de los paracas hasta el incanato.

- Iglesia del Señor de Luren. Su historia se remonta a la primitiva capilla levantada en 1558, que más tarde fue convertida en parroquia. En el interior del templo destaca la imagen del Señor de Luren, patrón de la ciudad. La fiesta patronal tiene lugar en la segunda quincena de octubre.

- Iglesia de La Merced. Ubicada en la Plaza de Armas, construida en 1759, es una iglesia de tipo colonial. En su interior hay un hermoso altar, y tres retablos en madera caoba y cedro nicaragüense.

- La Achirana. Según la leyenda de Ricardo Palma, Cápac Yupanqui, enamorado de la hija del cacique del lugar, mandó a construir a sus soldados el canal de la Achirana, el mismo que hasta hoy se utiliza.

- Laguna de Huacachina. A $5 \mathrm{~km}$ de la ciudad, se halla en medio de las dunas. Ofrece un bello paisaje $\mathrm{y}$, además, se cree que sus aguas poseen propiedades curativas.

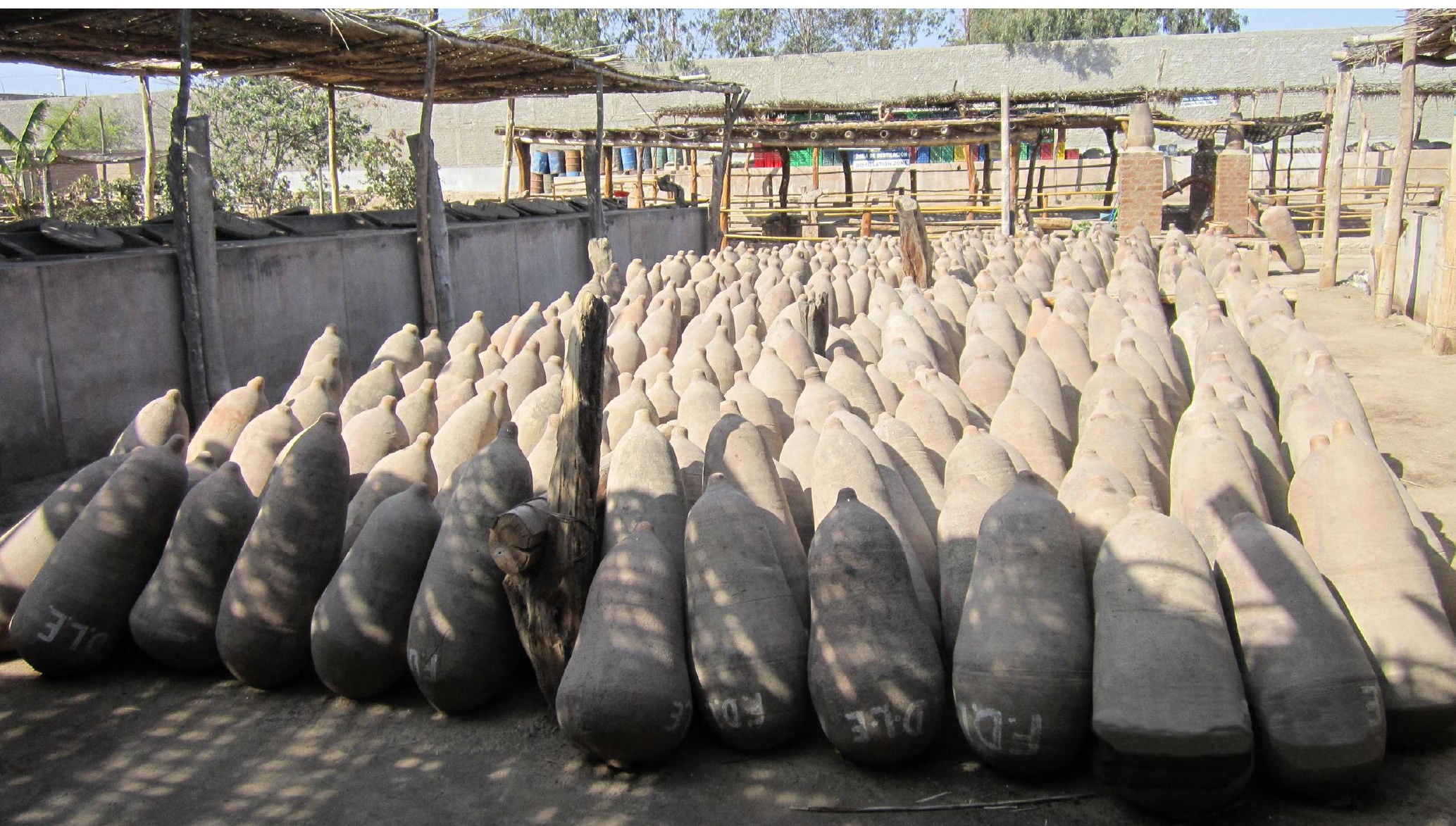


- Visita a las bodegas. Las bodegas grandes operan con maquinarias modernas para la producción de variedades de vino blanco y tinto, y piscos, que completan su elaboración en enormes pipas de roble instaladas en salones de penumbra. Algunas son la Bodega Lovera; la Bodega Hernández; la Bodega El Carmen; la Bodega Tacama, a 16 km; la Bodega Ocucaje, a 38 km de Ica; la Bodega Vista Alegre; la Bodega Álvarez; la Bodega Mejía; la Bodega San Alfonso; la Bodega Vista Alegre; y la Bodega Doña Mercedes.

La provincia cuenta con varios viñedos que forman parte de su patrimonio edificado, los cuales son aprovechados para el desarrollo turístico. Uno de los eventos más importantes es la Feria Internacional de la Vendimia, realizada anualmente en el mes de marzo, donde se promociona la producción de la uva, el pisco y el vino, lo cual se complementa con exposiciones de artesanía e industria (Municipalidad Provincial de Ica, 2008). Esta fiesta consiste en despojar a las parras de sus frutos. Tiene su origen en la época colonial, por lo que forma parte del patrimonio de la zona. Entre las actividades turísticas disponibles se encuentran las visitas a las principales bodegas.

Considerando que los viñedos son utilizados turísticamente, también podrían convertirse en museos comunitarios, y así lograr que los pobladores locales sean los principales beneficiarios de su propio patrimonio. Es por ello que en las siguientes líneas se brinda alcances respecto de las implicancias de la nueva museología y la participación de los museos en las dinámicas sociales.

\section{La Nueva Museología y la participación de los museos en las dinámicas sociales}

La tendencia en la museología mundial consiste en dejar de considerar a los museos solo como depósitos del patrimonio histórico y artístico de un lugar, y reconocerlos como instituciones integradas al contexto social y territorial, estrechamente relacionadas con las comunidades en las que desarrollan sus actividades. Estos cambios cobraron fuerza en la década del 70, cuando se empezaron a introducir por primera vez los conceptos de ecomuseo, museo participativo y museo comunitario, lo cual permitió que las comunidades tuvieran mayor injerencia en la salvaguarda de su patrimonio.

En todos los casos se trata de museos que no necesariamente están restringidos a mantener colecciones en vitrinas; es más, en muchos de ellos se llega a prescindir de un edificio continente. Dentro de sus funciones básicas está, en primer lugar, la conservación de las tradiciones, los hechos cotidianos de gran significado y valor para determinada localidad, a fin de que no se extingan. En segundo lugar, el mantener una comunicación fluida con la comunidad, en la que prime el espíritu participativo. En palabras de Hugues De Varine (1974), un verdadero ecomuseo es aquel donde se reflejan dos dimensiones importantes: la ya mencionada participación comunitaria, y la asesoría de expertos en museología, ya que, según De Varine, de lo contrario se corre el riesgo de nombrar ecomuseo o museo comunitario participativo a un espacio donde prevalecen los ideales y aspectos sentimentales sobre los lineamientos técnicos y científicos de la museología.

Según el International Council of Museums (ICOM),

La ética en el turismo cultural demanda de los agentes actuantes que el visitante combine el conocimiento creativo con el disfrute de su tiempo libre, favoreciendo principalmente que participe de un contexto social que, siéndole desconocido, le invita a participar en la vida y saberes locales de la comunidad anfitriona. $(2000$, p. 1)

Así, las nuevas propuestas museológicas se presentan como una manera atractiva de acercamiento cultural con personas de otros lugares, quienes pueden, mediante la observación y la interacción, comprender y apreciar el trabajo ancestral de los lugareños. Es importante resaltar que estos museos pretenden ayudar a las sociedades en la búsqueda y afirmación de sus identidades, además de permitir su participación activa en la salvaguarda de su patrimonio cultural. 


\section{Ecomuseo}

El concepto de ecomuseo fue planteado por el museólogo Hugues de Varien Bohan en 1971, y sus contenidos y fundamentos fueron desarrollados por G. H. Riviére, quien a mediados de los años 70 comenzó a considerar los problemas de identidad cultural, sobre todo en los grupos minoritarios. Ello lo llevó a repensar el concepto de museo y el rol que debía cumplir en la sociedad; es así que Riviére elabora el siguiente concepto de ecomuseo: "es un instrumento que el poder político y la población conciben, fabrican y explotan conjuntamente. El poder, con los expertos, las instalaciones y los recursos que pone a disposición; la población según sus aspiraciones, sus conocimientos y su idiosincrasia" (1985, p. 182). Hace énfasis en los conocimientos originales y tradiciones, y en la manera en que deben ser comunicados a través de las herramientas museológicas como exposiciones, talleres y cursos. Si bien la mayoría de estas experiencias se han desarrollado en Europa, Estados Unidos y Canadá, ya en los años 70 se plantearon las bases conceptuales para el desarrollo de museos con estas características en América Latina, mediante el denominado 'museo integral comunitario', que surgió como respuesta a las necesidades sugeridas en la Mesa Redonda de Santiago de Chile en 1972. Se trataba de un museo que mantenía semejanzas con el ecomuseo francés, en el que se inspiró la realización de la Casa Museo de México (Fernández, 2001). Existen otros antecedentes y experiencias relacionadas que permitieron dar forma al concepto de ecomuseo, mas se debe tomar en cuenta que este es un tipo de museo que continuará evolucionando junto con las demandas culturales de la sociedad. Entre los antecedentes está la Declaración de Oaxtepec (México) de 1984, en la cual se establece que los museos son una herramienta de desarrollo que deben de considerar la relación entre el patrimonio, el territorio y la comunidad; y la Declaración de Caracas de 1992, donde se analiza la realidad de los museos en Latinoamérica, y se observa las relaciones entre los museos y la identidad de la sociedad.

Se debe considerar también a los museos vecinales, que surgieron en los Estados Unidos a finales de la década de los 60, de los cuales el primero y más emblemático es el Museo Vecinal de Anacostia en Washington D.C. Este pertenece al Smithsonian Institute y su objetivo central, propuesto por John Kinard, fue responder a las necesidades de las comunidades más empobrecidas de las ciudades norteamericanas, sobre todo las minorías étnicas. A través de este tipo de museo, se logra que las comunidades se conviertan en participantes y creadoras de sus propios discursos culturales, mediante una mirada introspectiva y, sobre todo, empoderadora. Los ecomuseos surgen entonces como respuesta a las necesidades y deseos de las personas que viven y trabajan en el lugar, las cuales se deben involucrar de forma activa en cada fase del proyecto museológico, desde la planeación hasta el funcionamiento del mismo. De lo contrario, como manifiesta Varine en su ponencia Tomorrow's Community Museums (2003), se estaría replicando las formas de los museos tradicionales, los cuales "solo preservan el gusto de la minoría y la gran mayoría de la población no se encuentra interesada en su existencia" (De Varine-Bohan, 2003). Por este motivo, es necesario considerar los factores teórico-técnicos en el planeamiento, posterior desarrollo y ejecución de un museo de este tipo, cuyos objetivos y alcances intentan involucrar a toda la comunidad.

Es importante resaltar que estos museos pretenden ayudar a las sociedades en la búsqueda y afirmación de sus identidades, además de permitir su participación activa en la salvaguarda de su patrimonio cultural. Para Navajas (Alemán, 2011), el ecomuseo es "el museo que juega a la cultura contra lo cultural, con el pasado, el presente y hacia el futuro" (p. 116), un museo que es un proceso continuo e inacabado, porque sigue haciendo referencia a la evolución de la comunidad en la que está asentado. Navajas, propone parámetros para la ecomuseología, que son los que le dan características peculiares a este tipo de museos:

- Del patrimonio como una 'obra en proceso', que siempre está en constante evolución, cambio y renovación por parte de las comunidades, que luego lo convertirán, a su vez, 
en herencia para las generaciones venideras. En este sentido, el autor manifiesta que "el patrimonio forma continuamente una nueva colección" (Alemán 2011, p. 120) y que, por lo tanto, este proceso significa, para la nueva museología y la ecomuseología, que el proyecto museológico empieza por la comunidad antes que por la colección o el edificio donde estará el museo.

- La exposición y el museo como medios para generar un diálogo en la comunidad, y a través de estos transmitir los valores de identidad de la misma.

- Se asume la naturaleza del territorio como parte del museo; es decir, se trata de involucrar el paisaje y la comunidad, en tanto el equilibrio entre ambos se modifica constantemente y, con ello, el patrimonio y las formas socioculturales dentro de sí.

Cabe recordar en este punto que, si bien en la mayoría de definiciones los museos son descritos como espacios educativos sin fines de lucro, existen museos que se proponen como empresas, lo cual permite relacionarlos con las prácticas turísticas.

\section{Museos comunitarios}

Estos museos se convierten en espacios que permiten la construcción de discursos comunitarios (Gaboggi \& Melvilla, 2007) y, a la vez, muestran la realidad de la comunidad. Hugues de Varine (2005) define a estos museos como aquellos que surgen desde'abajo', en clara alusión a las comunidades, con la finalidad de responder a las necesidades y deseos de sus habitantes. Para él este es un esfuerzo compartido entre los pobladores, que participan activamente en la implementación y desarrollo de las actividades del museo, y los expertos, que apoyan a la comunidad en esta experiencia. A los museos comunitarios también se les puede conceptualizar como aquellos espacios donde la comunidad "realiza acciones de adquisición, resguardo, investigación, conservación, catalogación, exhibición y divulgación de su patrimonio cultural y natural, para rescatar y proyectar nuestra identidad, fortaleciendo el conocimiento de su proceso histórico a través del espacio y el tiempo" (Museo Cuitlahuac, 2002). Este concepto ya expresa las bases que sustentan este tipo de museos, donde los protagonistas son los pobladores locales; de ellos nace la idea de tener un museo y son ellos los dinamizadores de su cultura dentro del mismo.

\section{Turismo rural}

Cabe destacar que la creación de una nueva tipología de museos va relacionada al desarrollo del turismo rural en la zona.

Las definiciones de turismo rural varían, al igual que las de espacio rural, y han evolucionado a través del tiempo. La Comisión de las Comunidades Europeas lo define como "aquél que engloba a todas las actividades turísticas realizadas en un espacio rural" (Bote, 1992, p. 14). Esta definición es bastante amplia y poco explícita, por lo que es difícil determinar a qué elementos refiere exactamente, y puede fácilmente confundirse con lo que se considera agroturismo: "la hospitalidad de los agricultores en alojamientos restaurados a partir de antiguos edificios rurales y en espacios al aire libre para el camping, los servicios de alimentación o comidas a base de productos de la explotación y las actividades culturales y de ocio realizadas por los turistas en las explotaciones agrarias" (Bote, 1992, p. 14). Cabe resaltar que la definición brindada por la Comisión de las Comunidades Europeas ha sido la base de muchas otras adoptadas posteriormente por otros países para la realización de sus programas de turismo rural.

En 1995, Rafael Fuentes ofreció una definición más precisa de turismo rural, en la que agrupa varios componentes importantes para su desarrollo, como la descripción del espacio, las características de la oferta y la principal motivación de la demanda. Para el autor, el turismo rural es "aquella actividad turística realizada en espacio rural, compuesta por una oferta integrada de ocio, dirigida a una demanda cuya motivación 
principal es el contacto con el entorno autóctono y que tenga una interrelación con la sociedad actual" (Juan y Solsona, 2000, p. 10).

Por su parte, José Manuel Castaño (2005) aduce lo siguiente: "En líneas generales podemos definir el turismo en espacio rural como una oferta de actividades recreativas, alojamiento y servicios afines, situados en el medio no urbano y dirigido principalmente a los habitantes de grandes ciudades que buscan fundamentalmente un contacto con la naturaleza o con la población y la cultura tradicional" (p. 57).

Este concepto de turismo en espacio rural tiene mucho en común con el de ecoturismo, en cuanto a las motivaciones que movilizan a los turistas. Estas están presentes ambas tipologías. Sin embargo, en el caso del ecoturismo la apreciación de la naturaleza es supuestamente la motivación principal, mientras que en el turismo rural es el contacto con la población local.

Luigi Cabrini destaca la importancia del contacto con la población local para el turismo rural al considerar que la cultura rural es el componente clave del mismo, resaltando la personalización inherente a su prestación:

El término turismo rural se utiliza cuando la cultura rural es un componente clave del producto ofrecido. El rasgo distintivo de los productos del turismo rural es el deseo de ofrecer a los visitantes un contacto personalizado, de brindarles la oportunidad de disfrutar del entorno físico y humano de las zonas rurales y, en la medida de lo posible, de participar en las actividades, tradiciones y estilos de vida de la población local (lju, 2012, p. 8).

El Programa de Turismo Rural del Instituto de Desarrollo Agropecuario (INDAP) de Chile, establecido en 1995, define al turismo rural como "cualquier actividad turística realizada en un lugar rural incluyendo las áreas naturales. Es una actividad que integra a toda la familia campesina y resguarda sus costumbres y tradiciones" (Iju, 2012, p. 8). Años más tarde, en 2009, la INDAP complementa esta definición e incluye esta vez no solo a la familia campesina y su idiosincrasia, sino también al patrimonio natural y cultural de dichas zonas, y a la demanda:

...donde se describe como un tipo de turismo basado en el medio rural en un sentido amplio, que posee un interesante patrimonio natural, histórico - cultural y arquitectónico, que despierta el interés de las personas que habitualmente viven en el medio urbano y que están dispuestas a 'invertir' parte de su tiempo libre y recursos en reencontrarse en muchos casos con sus orígenes o simplemente explorar formas o lugares para vacacionar que se encuentran más allá de su tenor habitual. (Herrera, 2009, p. 3)

Por otra parte, en mayo del año 2000, se presenta el Programa Argentino de Turismo Rural Raíces, que considera como turismo rural "todas aquellas actividades que pueden desarrollarse en el ámbito rural y que resultan de interés para los habitantes de las ciudades por sus características exóticas, tradicionales, románticas, etc. Se caracteriza porque los servicios son prestados por los habitantes del mundo rural con la participación de la familia del productor agropecuario" (Secretaría de Agricultura, Ganadería, Pesca y Alimentación, y Secretaría de Turismo, 2000, p. 1).

En esta definición se resalta las características del espacio rural (exótica, tradicional y romántica) y la inclusión del productor agropecuario como prestador de los servicios turísticos. Cabe destacar que el Programa Argentino de Turismo Rural Raíces antecede al Proyecto Nacional de Turismo Rural (PRONATUR), lanzado en octubre de 2008. Este proyecto también brinda una definición de lo que es turismo rural, en la que lo considera como

....toda modalidad turístico - recreativa que se desarrolla en establecimientos del ámbito rural o en sus inmediaciones, y que permite al visitante conocer, compartir y aprender otras costumbres y tradiciones, a través de actividades cotidianas productivas y culturales, sensibilizándolo 
devenir Vol. 2, N4, JULIO-DICIEMBRE 2015, Pp. 9-26 - Estudios I ISSN 2312-7570

UNIVERSIDAD NACIONAL DE INGENIERÍ, LIMA

Figura 11. Campanario de Viñas Tacama

Fuente. Fotografía tomada por Saida Crisóstomo, 2013 sobre el respeto y valor de la identidad cultural de las comunidades y pueblos rurales. Incluye toda actividad que desarrolla el turista en el medio rural, siendo, en primer lugar, actividades de turismo rural aquellas que se realizan en los establecimientos agropecuarios que abren sus puertas (con o sin alojamiento) a las personas para observar ( $y$, eventualmente, participar) de actividades realizadas en el interior de uno o más predios. (Román, 2009, p. 15)

Esta definición brinda algunas consideraciones interesantes, como la interacción activa del turista con el poblador rural por medio de su participación en actividades cotidianas productivas y culturales; asimismo, hace mención a la sensibilización del turista con respecto al entorno.

La Organización Mundial del Turismo considera que el turismo rural es "todo aprovechamiento turístico en el ámbito del mundo rural, que tiene como protagonista principal y destinataria de sus frutos a la propia sociedad rural" (OMT, 2003, p. 2). Esta definición destaca la importancia del contacto con el entorno y, sobre todo, con la población local.

Para el Ministerio de Comercio Exterior y Turismo del Perú, el turismo rural comunitario es "toda actividad turística que se desarrolla en el medio rural, de manera planificada y sostenible, basada en la participación de las poblaciones locales organizadas para beneficio de la comunidad, siendo la cultura un componente clave del producto" (MINCETUR, 2008, p. 4).

Si bien la práctica del turismo rural es independiente de la existencia de un museo con características comunitarias, ello permite que se desarrollen una serie de aspectos que beneficiarían el turismo en la zona. En el caso de Ica, en primer lugar, se lograría poner en valor el patrimonio material edificado de los viñedos, ya que para albergar el museo debe de considerarse el espacio como parte de la experiencia; no

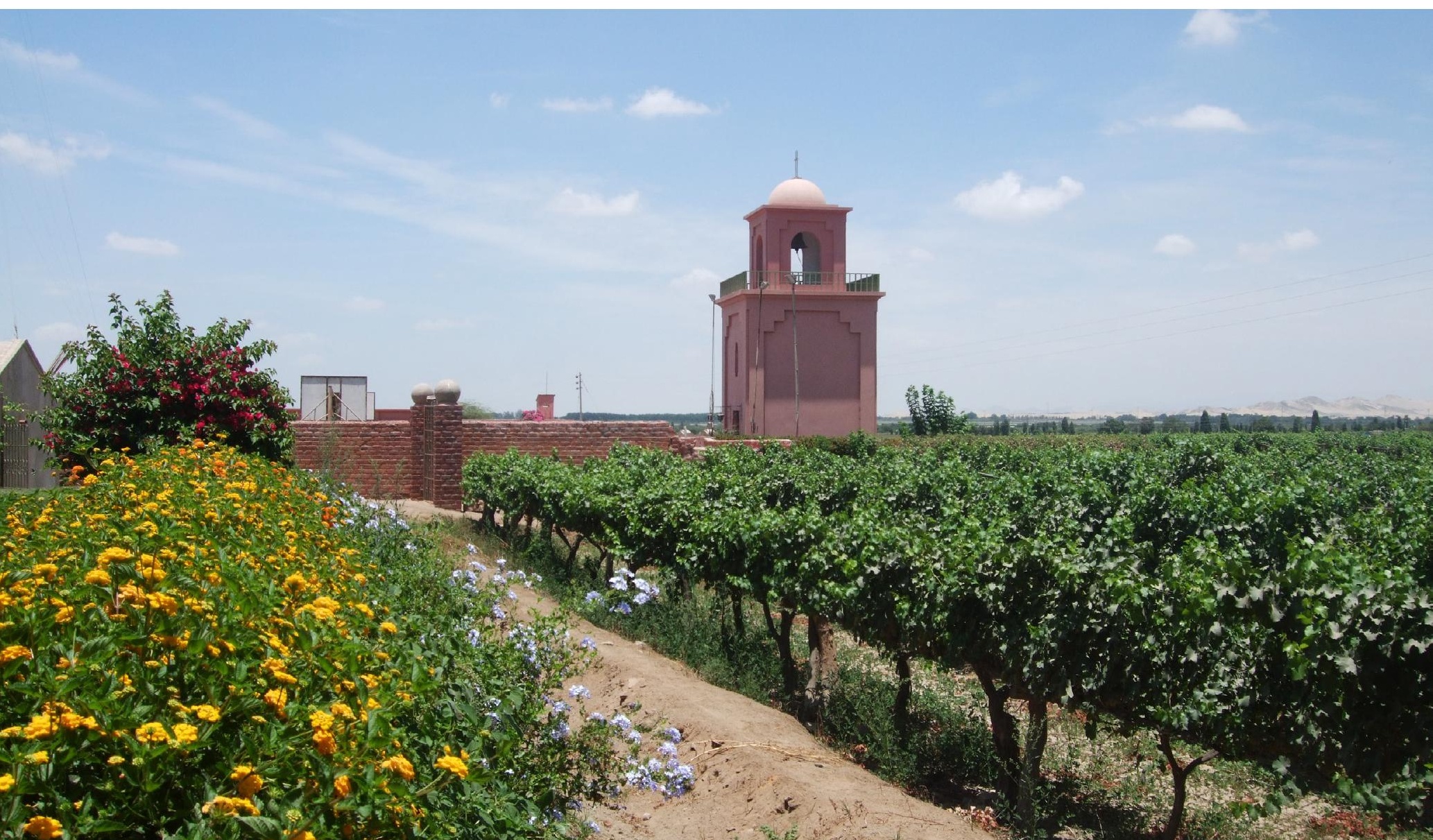


es lo mismo ver una exposición sobre viñedos en una sala adaptada en un museo clásico que verla en un viñedo tradicional, pues el contexto resulta impactante y significativo a la vez. En segundo lugar, la participación de la comunidad en la gestión y propuesta del museo generaría una relación más cercana con el patrimonio inmaterial, con las costumbres y la identidad cultural local, lo que traería beneficios que van más allá de lo económico.

En ese sentido, tanto la puesta en valor de los viñedos como la salvaguarda del patrimonio inmaterial asociado permiten que las actividades propias del turismo rural comunitario se realicen de forma armoniosa, aportando un recurso turístico más que puede ser visitado dentro de la oferta rural de lca.

Para llevar a cabo el turismo rural comunitario, es importante conocer las opiniones tanto de los pobladores locales como de los turistas que visitan la provincia. Es por ello que a continuación se presenta información sobre estos dos importantes actores del medio turístico.

\section{Ica bajo la mirada de sus pobladores}

Para evaluar la posibilidad de ofertar un producto turístico, hay que analizar a quienes podrían ofrecerlo; en este caso, se trata los pobladores locales de Ica. Para ello, se consideró conveniente realizar cuatro entrevistas a dos pobladores de la zona. Dos de ellas fueron conversaciones informales, a fin de conocer su interés en desarrollar el turismo rural, y las otras dos fueron entrevistas formales, que permitieron obtener un acercamiento más preciso sobre las actividades rurales que quisieran compartir con los turistas, así como las posibilidades de financiamiento disponibles para un eventual proyecto. También se realizó entrevistas adicionales a una docente universitaria y a un guía de turismo de la zona, para conocer, desde su experiencia, su punto de vista respecto al turismo rural en la zona y sus posibilidades de desarrollo.

Se priorizó la entrevista frente a las encuestas porque en este caso no se buscó representatividad estadística, sino conocer el interés por participar de este tipo de actividades, y metodológicamente la aproximación cualitativa resulta pertinente en estos casos a decir de los expertos (Valles, 1997; Merino, 2010). Cabe mencionar que se emplearon guiones de entrevista no estructurados, lo cual significa que, si bien algunos temas fueron comunes, no necesariamente se pueden comparar las respuestas.

\section{Entrevistado 1: Pedro Giurfa'}

La vivienda del entrevistado consta de un módulo de triplay con una cocina rústica y silo propio. Afortunadamente, cuenta con servicios básicos (agua, luz, desagüe, Internet, línea telefónica, etc.). A pesar de ser consciente de que su vivienda no es adecuada para recibir turistas, comenta que ha presentado a una entidad bancaria una solicitud de préstamo para un proyecto para construir alojamientos dentro de su terreno, que, en principio, ha sido aprobada.

Se le preguntó si para ello necesitaba asociarse, a lo que respondió que de momento solo está trabajando con su hijo, pero que en un futuro le gustaría contar con socios.

Su idea es construir dos áreas: una para personas que vivan allí de forma relativamente permanente y otra para turistas, mas su deseo es que ambas estén intercomunicadas para que se fomente el intercambio cultural.

\footnotetext{
1. Estudió en la Universidad Católica del Perú, donde llevó cursos de Educación, Arqueología y Arte.
}

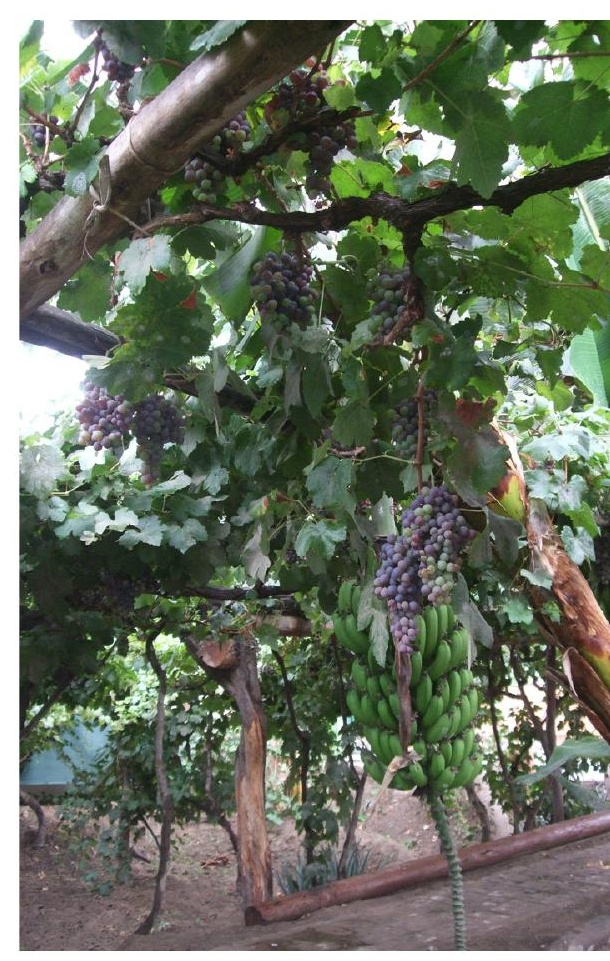

Figura 12. Uvas quebranta de la bodega Tres Generaciones.

Fuente. Fotografía tomada por Saida Crisóstomo, 2013 
Su intención es compartir con los turistas todas las actividades posibles: crianza de animales menores, floricultura, horticultura, manejo de la vid, elaboración de vinos y piscos, preparación de platos típicos, participación en festividades locales, labores de arqueología, caminatas a orillas del río, pesca artesanal y visitas guiadas. Cuenta también con un nuevo local en el que tiene proyectado elaborar quesos, yogurt y mermelada de frutas, actividades de las que también participarían los visitantes.

Se le preguntó si tenía acceso a una bodega artesanal donde elaborar vino. La respuesta fue afirmativa afirmó que era como su segundo hogar, y que el propietario también tiene la idea de recibir turistas ahí. De momento cuentan con dos alojamientos habilitados para recibir visitantes e impulsar el desarrollo turístico, pero actualmente no se les da uso. El entrevistado comenta que son lugares sencillos y limpios, y que uno de ellos cuenta con un pequeño museo, en el sentido tradicional del mismo, pero que podría fácilmente convertirse en un ecomuseo con la asesoría necesaria, de forma que se aproveche el espacio ya diseñado para recibir turistas.

Es notorio en el entrevistado el sentimiento de autoestima que le genera revalorar la cultura vinícola y la posibilidad de compartirla. Este es un aspecto importante a la hora de proponer la creación de un ecomuseo.

De esta primera entrevista se desprende que existe un enorme interés por desarrollar el turismo rural. Si bien es cierto que la vivienda del entrevistado aún no es adecuada para recibir visitantes, existe la posibilidad de obtener financiamiento para el desarrollo de un proyecto de este tipo.

\section{Entrevistado 2: Ricardo Otero ${ }^{2}$}

El entrevistado lleva dos años viviendo en Ica. Si bien es cierto que no es originario del lugar, se le seleccionó porque tiene interés en llevar a cabo proyectos de turismo y cuenta con los medios económicos para ponerlos en práctica.

Él ha construido una vivienda de adobe, material muy accesible en la zona, con interesantes cualidades como aislante térmico. Es una vivienda transitoria que se construyó provisionalmente para la primera fase del proyecto. Este es de corte turístico-ecológico y se centra, básicamente, en el proceso de regeneración natural del agua, del cual tomaría parte el turista.

A nivel de infraestructura cuenta con un arroyo de aproximadamente 210 metros de largo por tres de ancho y uno de profundidad; tiene islas, una península grande con árboles y caídas de agua. Según menciona el entrevistado, en Europa funcionan ese tipo de proyectos. Para la segunda fase, tiene planeado construir una sala de recepción, y terrazas donde los visitantes puedan comer, beber y disfrutar de la vista. La casa no ha sido utilizada con fines turísticos aún, ya que el terreno no está habilitado, pero si las dos primeras etapas fuesen exitosas, en la tercera implementaría un hospedaje con una temática específica: las culturas prehispánicas. Asimismo, de momento tiene acceso a una bodega artesanal para la elaboración de vino y pisco, pero pronto construirá una propia.

Con respecto a las actividades que compartiría con los turistas, menciona las siguientes: el funcionamiento del ciclo del agua, la vida en el campo, labores de arqueología (limpieza), procesos de elaboración de vino y pisco, sesiones de yoga, escalada en palestra, entre otros. Vale mencionar que un ecomuseo se presenta como una idea compatible con lo que viene haciendo el señor Otero. Al mostrar de forma dinámica su entorno real, el espacio se convierte en parte del discurso museístico.

2. El segundo entrevistado es de nacionalidad venezolana. Estudió la carrera de Turismo durante dos años y es licenciado en Comercio. 


\section{Entrevistas adicionales}

Adicionalmente a estas cuatro entrevistas a pobladores locales, se registró conversaciones informales con la profesora Saida Crisóstomo, docente del curso Zonas, circuitos y paquetes turísticos de la Universidad Alas Peruanas de Ica, quien da cuenta de la importancia de diversificar la oferta turística de la zona por medio del turismo rural.

La docente manifestó que esto era necesario, ya que los paquetes turísticos se concentran en torno a la Huacachina, algunas bodegas de vino y, ocasionalmente, en lo que se denomina la Ica arqueológica, que incluye los sitios Huaca Guadalupe, Tacaraca y Cerrillos. Sin embargo, aclara que ninguno de estos tres sitios cumple con las condiciones para ser ofertados a los turistas, por lo cual considera que Ica está por desaparecer como destino turístico, dado que la oferta de Paracas y Nasca resulta más atractiva.

Finalmente, comenta que mediante la docencia ella busca que sus alumnos sean creativos al elaborar paquetes turísticos, que desarrollen sus inventarios y creen programas de agroturismo.

Ante esta situación, el diseño de ecomuseos relacionados al tema del vino y del pisco, que proponemos en este artículo, podría dinamizar la oferta turística en Ica, aprovechando un recurso tradicional que, además, pone en valor espacios monumentales que de otra manera están condenados al olvido.

\section{Ica, bajo la mirada turística}

Es importante considerar el perfil del turista que visita esta provincia. En una investigación realizada en 2012 por lju, de una muestra de 460 visitantes al mes, se observa que la edad de los mismos fluctúa entre los 18 y 30 años, y que más del $90 \%$ cuenta con estudios superiores. Además, el $73,5 \%$ proviene de la ciudad de Lima y generalmente viaja con los amigos o la familia, y el $36 \%$ permanece durante dos días en la zona. Asimismo, las personas visitan la provincia de Ica básicamente por su buen clima, para hacer turismo de aventura y visitar las bodegas vitivinícolas.

Es resaltante que las motivaciones para visitar Ica que muestran los porcentajes más altos no llegan al $51 \%$, por lo cual se podría deducir que no existe una motivación predominante para viajar a Ica, y que solo es visitada por su cercanía a Lima o porque es un lugar de paso hacia Nasca. Es por ello que Saida Crisóstomo afirma en la entrevista realizada que Ica está por desaparecer como destino turístico. La implementación de museos comunitarios basados en sus viñedos, así como el desarrollo del turismo rural, podrían ser una alternativa de diversificación de la oferta, en pos de la sostenibilidad local (lju, 2012).

En el mismo estudio se han obtenido datos acerca de las actividades que desearían realizar los visitantes; la opción 'participación en la elaboración de vinos y piscos' obtuvo una aceptación de $64,6 \%$, por lo cual promover el cuidado y uso adecuado de los viñedos como parte del patrimonio edificado se presenta como una alternativa interesante de desarrollo para la provincia (lju, 2012).

Las actividades vitivinícolas son preferidas también por las personas que viajan por primera vez a Ica, y que permanecen ahí por dos o tres días (un promedio de 65 y 42 personas al mes respectivamente). Este patrón se repite en cuanto al rubro gastronómico, lo que indica que estos visitantes buscan otras actividades aparte de las que tradicionalmente se ofertan en Ica. Según la entrevista a Saida Crisóstomo, la zona se conoce en 3 o 4 horas, por lo que, en el caso de turistas que han decidido permanecer durante dos o tres días, conocer la Huacachina, la ciudad y las bodegas vitivinícolas resulta insuficiente. Nuevamente, diversificar la oferta se convierte en un aspecto fundamental a desarrollar. 
Es importante destacar también el promedio de gasto diario en Ica. La mayoría, el $42,2 \%$ de los encuestados, indica haber gastado entre 50 a 100 nuevos soles, mientras que $28,7 \%$ gastó entre 100 a 150 . El porcentaje más bajo es de $3,5 \%$, representado por aquellos visitantes que invirtieron de 250 a 300 nuevos soles al día.

A su vez, es relevante mencionar las veces que los turistas han visitado la provincia. El $46,1 \%$ de los encuestados visitaba Ica por primera vez, mientras que el $22.6 \%$ lo hacía por segunda vez. Lo más resaltante es que un 19,3\% manifestó haber viajado a la zona cuatro veces o más, lo que indica que existe un público fiel que constantemente va a la zona.

Según la información brindada por los encuestados, las razones principales de su visita son el buen clima $(50,9 \%)$, el paseo en tubulares $(45,2 \%)$ y la visita a bodegas vitivinícolas (33,9\%), por lo cual la creación de museos comunitarios, tomando en consideración los viñedos, junto al desarrollo del turismo rural, puede ser una alternativa interesante de desarrollo local (lju, 2012).

A ese respecto, el 53,9\% de los encuestados manifestó que sí se trasladaría a la zona únicamente para realizar actividades rurales, mientras que el $46,1 \%$ afirmó que no lo haría. Esto indica que si se decidiese llevar a cabo algún proyecto de turismo rural, este podría ser exitoso.

A su vez, mientras que el $78,3 \%$ de encuestados respondió que estaría dispuesto a hospedarse en casas de pobladores locales, el 21,7\% manifestó lo contrario. El porcentaje de las respuestas afirmativas es bastante alto, por lo cual se puede inferir que si los pobladores decidieran ofrecer sus casas como hospedaje, estas tendrían demanda por parte de los turistas (lju, 2012).

\section{Conclusiones}

Los museos, cada vez más, están llamados a responder a las necesidades culturales y de representación de las comunidades donde se erigen; es a partir de ese paradigma que se han desarrollado museos que buscan la participación activa de las comunidades.

La nueva museología, al apartarse de las estructuras clásicas, ha permitido la evolución del concepto de 'museo'; se ha encontrado diferentes medios de conectar la cultura y el patrimonio con la comunidad. De esta manera, el mismo deja de ser una imposición externa; por el contrario, se funda en una decisión de la comunidad. Esto es importante sobre todo en contextos donde la comunidad siente que su patrimonio está en vías de extinción. En el caso de Ica, además, esto permitiría la identificación de los signos y de la tradición vitivinícola como parte de sus raíces culturales.

La base de este tipo de museo es el trabajo comunitario: aspira a convertir a los pobladores en actores de su proceso cultural, en vez de observadores pasivos. Para ello es indispensable contar con un comité, u otro tipo de organización vecinal, que pueda llevar a cabo las coordinaciones del museo, tanto con los demás miembros de la comunidad como con los especialistas y profesionales que los asesoren. La comunidad provee los recursos para organizar e implementar el museo, lo cual les brinda mayor autonomía sobre las decisiones y facilita la autogestión. Una experiencia organizativa exitosa promueve otras iniciativas en este campo. La comunidad se apropia de la gestión y siente al museo como propio, lo cual promueve y fortalece la identidad local.

En el caso específico de Ica, la creación de un museo comunitario sería bastante interesante como forma de darle más valor a los viñedos y, a su vez, contribuir con la economía local, considerando que los principales beneficiarios son los pobladores. Conservar los viñedos significa dar valor a su patrimonio edificado, valor que permitiría que se conserven en buen estado gracias al ingreso económico de los visitantes. Además, no solo se verían incrementadas las rentas locales, sino que los lugareños, al ver el interés 
que los visitantes ponen en sus atractivos turísticos, reforzarían su identidad cultural y el orgullo por su patrimonio.

Con respecto al turismo rural, cabe destacar que una de las actividades que más gustarían de realizar los turistas es participar en la elaboración de vinos y piscos $(64,6 \%)$, principalmente aquellos que viajan por primera vez, y que permanecen entre 2 y 3 días en la zona. Por lo tanto, si las comunidades se decidieran a implementar este proyecto, las labores de promoción deberían estar dirigidas a este público objetivo.

Fue posible apreciar que los visitantes que se trasladarían a Ica únicamente para conocer las actividades rurales es relativamente alto $(53,9 \%)$, por lo cual se podría articular a la oferta turística tradicional las iniciativas que mayor demanda tienen, a manera de pilotos, para que poco a poco se hagan conocidas y ganen presencia en el mercado. El ecomuseo, por ejemplo, podría formar parte de estas propuestas; con el mismo se generaría una actividad más dentro de la oferta turística, lo cual siempre es atractivo para los visitantes.

\section{Reflexión final}

La nueva museología y el turismo rural pueden ser dos grandes pilares para lograr convertir a Ica en una provincia turísticamente interesante, con una oferta variada y cautivadora, donde los viñedos tomen un rol destacable dentro del desarrollo socioeconómico local.

De esta manera, además de salvaguardar el patrimonio edificado, se lograría la participación social, lo que garantiza la sostenibilidad de las acciones realizadas, la preservación de la cultura y tradición vinícola, y el desarrollo del sentimiento de orgullo y autoestima en los agentes locales.

\section{Agradecimientos}

Agradecemos mucho a las personas entrevistadas, quienes fueron de mucha ayuda para la realización de este artículo:

A Saida Crisóstomo, docente universitaria de Ica con especialidad en turismo

A Pedro Giurfa y Ricardo Otero, pobladores de Ica con emprendimientos de turismo rural comunitario

\section{Bibliografía}

Alemán, A. (2011). Los Museos Comunitarios Participativos. Una Aproximación a la Nueva Museología. Cultura (25),113-125.

Bote, V. (1992). Turismo en espacio rural. Rehabilitación del patrimonio sociocultural y de la economía local. Madrid, España: Editorial Popular.

Castaño, J. (2005). Psicología social de los viajes y del turismo. Madrid, España: Thompson.

De Carli, G. (2004). Vigencia de la Nueva Museología en América Latina: conceptos y modelos. Revista Abra, 24(33), 55-75.

De Varine-Bohan, H. (2003). Tomorrow's community museums. Recuperado de http://assembly. coe.int/Museum/ForumEuroMusee/Conferences/tomorrow.html

De Varine-Bohan, H. (1974). Los museos del mundo. España: Salvat.

Fernández, L. A. (2001). Museología y museografía. Madrid, España: Ediciones del Serbal.

Gamboggi, A. y Melville, G. (2007). Museo comunitario como tecnología social en América Latina. Revista Digital Nueva Museología. Recuperado de: http://nuevamuseologia.net/museo-comunitario-como-tecnologia-social-en-america-latina/ 
devenir Vol. 2, N4, JULIO-DICIEMBRE 2015, Pp. 9-26 - Estudios I ISSN 2312-7570

UNIVERSIDAD NACIONAL DE INGENIERÍA, LIMA

Herrera, R. (2009). Estudio sobre turismo rural en Chile. Valdivia, Chile: Instituto Interamericano de Cooperación para la Agricultura.

lju, N. (2012). Espacio turístico rural (Tesis de doctorado sin publicar). Universidad de San Martín de Porres, Lima, Perú.

Juan, F. \& Solsona, J. (2000). Alojamiento turístico rural. Gestión y comercialización, Madrid, España: Síntesis.

Merino, M. (2010). Introducción a la Investigación de Mercados. Madrid: ESIC.

Morales, T., Camarena, C. \& Valeriano, C. (1994). Pasos para crear un Museo Comunitario. Ciudad de México: Instituto Nacional de Antropología e Historia - Dirección General de Contabilidad Pública.

Ministerio de Comercio Exterior y Turismo, MINCETUR (2008). Lineamientos para el Desarrollo del Turismo Rural Comunitario en el Perú, Lima: Autor.

Municipalidad Provincial de Ica. (2008). Plan Vial Provincial Participativo de Ica 2008-2017. Ica, Perú: Autor.

Museo Regional Comunitario del Distrito Federal- México: Museo Cuitlahuac. http://cuitlahuac. org/c/sec_2.htm

Organización Mundial del Turismo (2003). Taller del Programa Nacional para el Desarrollo del Turismo Rural en el Perú. Lima, Perú: Autor.

Rivière, G.H. (1985). Definición evolutiva del ecomuseo. Museum, XXXVII 148, 202-203.

Secretaría de Agricultura, Ganadería, Pesca y Alimentación, \& Secretaría de Turismo. (2000). Programa Argentino de Turismo Rural. Buenos Aires, Argentina: Autor.

Sotil, R. (2005). Ica. Apuntes monográficos. Lima, Perú: Universidad Alas Peruanas. Recuperado de http://www.unwto.org/regional/europe/

Valles. M. (1997) Técnicas cualitativas de investigación social. Madrid, España: Síntesis. 